\title{
The Effect of Nouns and Verbs of the Same Word on Lexical and Structural Development in the Writings of Iraqi EFL Secondary School Students
}

\author{
Jasim Mohammed Abbas
}

\begin{abstract}
In English language, like the vast of languages, a big number of words are utilized to occupy more than one position; these words can be used as both nouns and verbs. Such case brings problems for EFL students aiming to learn the grammatical properties of words. Therefore, it, to a wider or lesser extent, has an effect on the lexical and structural development of the students' written texts. This paper sheds light on the difficulties faced by Iraqi EFL secondary school students in the perception and use of the words that could be both nouns and verbs. For achieving this, the study employed a writing test consisting of two parts which was conducted by 15 students. In the first part, the students were given 10 sentences and asked to form nouns and verbs out of given underlined words whereas the second part included 10 sentences in which the students were asked to identify if the given bold word is a noun or a verb. The findings, based on a quantitative analysis, indicated that a majority of the participants were unable to use nouns and verbs having the same word in their writings. The findings also showed that participants were unaware of these nouns and verbs. Most of the students could not recognize the given words whether they were nouns or verbs.
\end{abstract}

Keywords: nouns, verbs, lexical, structural, grammatical category

\section{Introduction}

In any language, there is a close connection between a grammatical category and a lexical knowledge which is stored in a learner's brain. Based on this relationship, the organization of lexical knowledge depends fully on grammatical category information. Thus, language proposes "infinite use of finite means" (Von Humboldt, 1999) by means of relating certain known words in a sequence of sentences. Words are not restricted to particular linguistic contexts in which they have been previously employed, nor could they be used freely in any context. In the whole process, the syntactic contexts in which words may occur are governed by their grammatical categories: noun, verb, adjective, or adverb.

The case in which EFL learners can perceive and use the different grammatical categories (parts of speech) seems to be more difficult than that of native speaker students or even than that of ESL learners. This difficulty of students' perception and use of grammatical categories is explained in a clearer way when it is related to nouns and verbs having the same words since students have not been exposed before to the types of these words or trained to use them in their writings. EFL students are learned more how to recognize a noun or a verb by identifying its position in a sentence. For example, a noun usually occupies the beginning or the end of a sentence. On the other hand, a verb comes in the second position in a sentence. In English, nouns tend to be acquired earlier than verbs and accessed more easily (Goldfield, 2000, De Bleser \& Kauschke, 2003).

\section{Significance of Using Nouns and Verbs of the Same Word in Writing}

The utilization of a grammatical category in language refers to the way a word behaves syntactically. For example, nouns could be subjects of verbs, objects of verbs, objects of prepositions, indirect objects, and so forth. Conwell and Morgan (2011) state that knowledge of category membership allows speakers to employ words productively in various contexts which are different from contexts in which particular words have been heard.

A main task for language learners is to decide which words in the language belong to which categories. Therefore, the present paper aims to provide an insight of how Iraqi EFL secondary school students can perceive and use nouns and verbs of same words in their writings. This case poses a particular challenge to EFL learners in general and Iraqi students in specific. 
A number of past studies tried to deal with this problem from different aspects and provide remedies to solve it. According to Hohle, Weissenborn, Keifer, Schulz \& Schmitz, 2004; Monaghan, Chater, \& Christiansen, 2005, this problem could be solved when learners could use local co-occurrence cues to learn the categories of words. Other researchers suggested that grammatical categories are better explained through a connection to distributional cues in corpora of child-directed speech (Redington, Charter, \& Finch, 1998; Mintz, Newport, \& Bever, 2002; Mintz, 2003; Mintz). However, these cues could only prove an accurate output of grammatical categories. The connection between lexical items and its grammatical categories is still not considered in the above solutions (Cartwright \& Brent, 1997).

\section{2 Effect of the Perception of Nouns and Verbs of the Same Word on Lexical and Structural Development}

As nouns and verbs are two grammatical categories which are both important in language syntactically and semantically, the process of storing them in the learner's mind doesn't occur at the same time. In this regard, Kauschke and Stennken (2008) provide new experimental evidence from online processing supporting earlier findings from numerous studies revealing that nouns are processed faster than verbs.

Noun- verb distinction could also be psychologically real and relevant at the lexical level based on a priming study by Melinger and Koening (2007). In their study, they investigated whether grammatical information influences the lexical selection of single words or whether such information is determined while inserting single words into larger syntactic units. In this regard, phonological, semantic and syntactic information about words is not stored as a single whole within the mental lexicon. Instead, it is rather represented in different aspects. Each type of this information can be accessed independently. The influence of phonological and semantic information on lexical selection of single words is evident (Shelton and Martin, 1992; Kroll and Stewart, 1994; McRae and Boisvert, 1998). The process is explained by referring to the idea that words are organized in the mental lexicon in form of a network including phonologically and semantically related nodes. The relationship between mental lexicon and syntactic features was also clarified further by numerous studies which suggested that syntactic information, in fact, exerts an influence on a lexical selection when an accessed word is integrated into unfolding syntactic representation (Ferreira and Humphreys, 2001; Vigliocco et al., 2004). This indicates that speech errors are subject to grammatical category constraints. For instance, in word substitutions, the interacting words are derived from the same syntactic category: nouns exchange nouns, verbs exchange verbs. However, this influence of grammatical category on lexical selection is only seen when a certain given lexical candidate is to saturate some slot in the unfolding syntactic derivation. In some different view, Melinger and Koenig (2007) argue that grammatical category information is available whenever needed irrespective of whether a single word, a phrase or a whole sentence is produced. This gives evidence that the effect of syntactic information should be observed even if there are combinatory processes involved. Accordingly, the perception of nouns and verbs of the same word in the mind of the learners as syntactic information will add to the lexical selection and contribute to the lexical and syntactic development in speech and writing as well.

\section{Purpose of the Study}

Since nouns and verbs of the same words could affect EFL learners' written texts, the study aims to achieve the following objective:

To examine the extent to which Iraqi EFL secondary school students could perceive and use nouns and verbs of the same word in their writings.

\section{Methodology}

\section{1 Participants}

The participants in this study were 15 secondary school students (8 female and 7 male). The sample of the study, according to Creswell (2005) and Maxwell (1998) is purposive. Maxwell asserts that purposive sample is "particular setting, persons, or events are deliberately selected for important information they can provide that cannot be gotten as well from other choices" (87). Secondary school students are expected to be suitable for the study to attain its objective since they are expected to deal with different types of grammatical categories (parts of speech) in their syllabus. Above, the students in this level of their study encounter serious problems in distinguishing between the various kinds of parts of speech particularly in the case of nouns and verbs of the same words. All participants share the same linguistic, cultural and educational background. For instance, they were all Iraqi EFL secondary school students with Arabic as L1. 


\section{2 Instrument and Procedure}

A writing test was used in this study. The test included two parts (questions) and aimed to examine the students' ability to perceive and use different types of nouns and verbs having the same words in different sentence positions. The first part consisted of 10 items which aimed to elicit information about students' ability to use different kinds of nouns and verbs with a cross-category usage of the same word. In this part, the students were asked to employ a verb out of an underlined noun and vice versa. Each item included two sentences; each one had one grammatical category (a noun or verb). The underlined words in the ten sentences occupied various sentence positions (e. g., a subject, a verb, or an object). The second part intended to test the students' perception of nouns and verbs having the same word employed in writing. It also consisted of ten items; each item included only one sentence. The students were asked to identify whether a given bold word is a noun or verb. The bold words in the ten sentences also occupied different sentence positions.

Before conducting the main study, the researcher carried out a pilot study for both the two parts of the writing test to 5 students. In both parts (questions), the students raised some questions about how to change the underlined word to a noun or a verb. Based on the questions raised by the students, they were told to follow the instructions supplied to them by their teachers and as assigned in the syllabus. The subjects assured that the two parts of the test given to them were not difficult to understand. The response to the test depends on the previous knowledge that the students had through their school study.

A week later, the test was administered to the 15 subjects who were given one hour to answer the two parts of the test. In fact, they were informed that this test is of great benefit for the students since it helps them improve their writing skill. They were also told to write their answers on the same sheets of questions and pay more attention making their answer look clear.

In order to make it easier for students to complete, a number of issues were considered in the process of choosing the sentences of the writing test. The researcher aimed at selecting those sentences which could be available in their textbook that may be familiar to them. In addition, one of the important considerations in the process of selecting the words and sentences was the extent to which they can induce the participants to use different words of cross-category usage.

\section{3 Model of Analysis}

English has many words which can be employed in more than on grammatical category. As stated earlier, these words pose real problems for EFL learners and particularly for Iraqi EFL secondary school students. Below are samples of words that are both nouns and verbs arranged alphabetically. These words could act as a base on which the students' writings are analyzed in reference to the use of nouns and verbs having cross-category usage.

[access, act, aim, answer, attack, ache, address, alert, arrest, auction] [back, bare, benefit, board, break, bail, balance, blame] [cake, chant, cloud, cook, call, change, clue, care, color, copy, chip, comfort, cover, claim, crack, cut, change] [dam, delay, dislike, doubt, drink, damage, delight, die, drill, dye]

[echo, escape, estimate, excuse, experience, email, eye] [face, fight, fix, flow, form, fall, file, flap, flower, flash, fly, fish, floss, force] [garden, glue, grill, guess, gaze, grate, guide, gel, guard]

[hammer, harness, heat, hit, hug, hand, hate, hold, head, hop, hope, hurry, hike, hose] [ice, inch, influence, itch, impact, insult, iron] [jail, jam, joke, judge, jump] [keep, kiss, knock, kick, knit, knot] [label, license, limit, lock, land, lead, lock, last, light]

[mail, march, matter, moor, mark, move, man, match, mug, mate, milk, mistake] [nail, need, notch, notice, name, nest, note, number] [object, offer, oil, order]

[pack, pat, pick, plug, process, paddle, pay, produce, plant, post, part, permit, pump, pass, phone, play, punch, present] [question, quilt, quiz] [race, rate, rent, rain, repair, ring, reason, reply, riot, ruin, record, report, rock, run]

[sail, shop, smell, smile, struggle, study, season, skate, storm, swap, share, slide, stress, shelter, slip, shock] [tack, thunder, tire, trade, taste, tick, tug, telephone, tip, treat, type, test, trick] 
[upstage, use] [vacuum, value, visit, voice, vote] [walk, water, worry, waltz, wave, wish, wrap, wear, wick, work, watch, wink] [yawn, yield] [zone]

The above- mentioned words are different in use. In some cases, as in (1), the word is considered as inherent member of one category and the other use is derived (Clark \& Clark, 1979). In other cases, the two words used are merely synchronically homophones, as in (2).

(1) We will walk to the store.

We take a walk tonight.

(2) We will fly to London tomorrow.

We swatted the fly.

This kind of category ambiguity has been taken as evidence against the logical possibility of learning grammatical categories from distinction (Pinker, 1987). The difficulty encountered with these words is attributed to the fact that their ambiguous status may cause native learners in general and ESL/EFL learners in specific conflate co-occurrence information across categories.

\section{Data Analysis}

The data collected in this study were analyzed quantitatively. The results are explained in detail below.

Table 3. 1 Participants' Use of Nouns and Verbs of the Same Word

\begin{tabular}{lllll}
\hline $\begin{array}{l}\text { No. of } \\
\text { Item }\end{array}$ & Correct & $\%$ & Incorrect & $\%$ \\
Responses & & Responses &
\end{tabular}

\begin{tabular}{lllll}
\hline $\mathbf{1}$ & 8 & 53.3 & 7 & 46.7 \\
$\mathbf{2}$ & 3 & 20 & 12 & 80 \\
$\mathbf{3}$ & 4 & 26.7 & 11 & 73.3 \\
$\mathbf{4}$ & 7 & 46.7 & 8 & 53.3 \\
$\mathbf{5}$ & 10 & 66.7 & 5 & 33.3 \\
$\mathbf{6}$ & 5 & 33.3 & 10 & 66.7 \\
$\mathbf{7}$ & 6 & 40 & 9 & 60 \\
$\mathbf{8}$ & 4 & 26.7 & 11 & 73.3 \\
9 & 4 & 26.7 & 11 & 73.3 \\
10 & 9 & 60 & 6 & 40 \\
Total & 60 & 40 & 90 & 60 \\
\hline
\end{tabular}

Table 3. 1 shows that Iraqi EFL secondary school students encounter serious problems in using nouns and verbs of the same word in their writings as the total number of their correct responses to the first part of the test $(40 \%)$ is lower than that of their incorrect ones $(60 \%)$. Consequently, the hypothesis that reads: Most of the Iraqi secondary school students do not use words that are both nouns and verbs in their writings is verified.

Table 3. 2 Participants' Perception of Nouns and Verbs of the Same Word

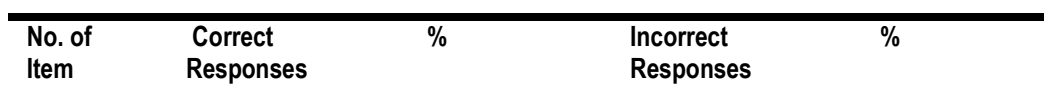

\begin{tabular}{llcc}
6 & 40 & 9 & 60 \\
\cline { 2 - 2 } & & \\
& 59 &
\end{tabular}




$\begin{array}{lllll}\mathbf{2} & 11 & 73.3 & 4 & 26.7 \\ \mathbf{3} & 5 & 33.3 & 10 & 66.7 \\ \mathbf{4} & 9 & 60 & 6 & 40 \\ \mathbf{5} & 3 & 20 & 12 & 80 \\ \mathbf{6} & 5 & 33.3 & 10 & 66.7 \\ \mathbf{7} & 4 & 26.7 & 11 & 73.3 \\ \mathbf{8} & 10 & 66.7 & 5 & 33.3 \\ \mathbf{9} & 8 & 53.3 & 7 & 46.7 \\ 10 & 12 & 80 & 3 & 20 \\ \text { Total } & 73 & 48.7 & 77 & 51.3\end{array}$

From the table above, it can be concluded that most of the participants' responses to the second part of the test are incorrect. This means that the students' writings have flunked to employ words that are both nouns and verbs. It is clear that they have difficulty to understand and identify those words with cross-category usage since their syllabus and teachers have not presented in detail previously. This is quite apparent since the incorrect responses are (51.3\%) higher than the correct ones $(48.7 \%)$.

The findings of the study also show that the words that the students manage to use more are the nouns, face, address, and fly with $(66.7 \%, 53.3 \%$ and $46.7 \%)$ respectively. It can be concluded that these nouns are used frequently in their syllabus. Therefore, they use them more than others. On the other hand, the students use the verbs, hope and mark more than other verbs with (60\% and $40 \%)$. In reference to the participants' perception of the given words in the second part of the test, the words presented, influence, and report are the highest in the students' perception with $(80 \%, 73.3 \%$ and 66 . $7 \%$ respectively.

\section{Discussion of the results}

The quantitative analysis has revealed that the correct responses in the two parts of the written test are lower than the correct ones. The students fail to perceive and employ most of the words (nouns and verbs) given to them in the test. Words like care, smell, insult, water and break seem very strange and unfamiliar to them. Only three or four students could perceive and use these words. This may mean that such words have not been supplied to them and not been explained by their teachers. On the other hand, the students find difficulty in using the different words provided to them in the test. They fail to employ nouns out of the verbs mentioned in the first five sentences and they also fail to use verbs out of the nouns given in the other five sentences in the first part of the test. Only words like hope, address, and face are familiar to most of the students. This is attributed to the fact that these words have been focused on by their teachers and the syllabus as well.

\section{Final Remarks}

1. The analysis of the data has shown how problematic inconsistent knowledge. In many cases, the students have failed to identify the words given to them in the test as being nouns and verbs of the same word that are frequently used in the English writing.

2. Iraqi EFL secondary school students are not sufficiently able to use words of cross-category usage. They manage to use only those words which are familiar to them in their syllabus. As a result, it seems that their writings lack lexical and structural development.

3. It is observed by the researcher that pedagogically clear instruction design for words of cross-category usage can help secondary school EFL learners perceive and use these words. This is because that these students seem to have a limited experience of words that are both nouns and verbs and therefore tend to rely on a small number of these words. Thus, the students' weakness in their perception and use of words that are both nouns and verbs could be treated seriously by both the syllabus and the teachers by means of supplying the students with different words of cross-category usage illustrated by a sufficient number of examples. Teaching these words is better given in early stages in secondary school.

\section{References}

[1] Cartwright, T. A., and Brent, M. R. (1997). Syntactic categorization in early acquisition: Formalizing the role of distributional analysis. Cognition, 63, 121-170.

[2] Clark, E. V., and Clark, H. H. (1979). When nouns suffer as verbs. Language, 55, 767-811. 
[3] Conwell, E., and Morgan, J. L. (2011). Is it a noun or is it a verb? Resolving the ambicategoricality problem. Language Learning and Development, 8, 87-112.

[4] Creswell, J. W. (2005). Educational Research. (2 ${ }^{\text {nd }}$ ed. ). Pearson Education.

[5] De Belser, R., and Kauschke, C. (2003). Acquisition and loss of nouns and verbs: parallel or divergent patterns? Neurolinguistics, 16, 213-229.

[6] Ferreira, V. S., and Karin, R. H. (2001). Syntactic influences on lexical and morphological processing in language production. Journal of Memory and Language, 44, 52-80.

[7] Goldfield, B. A. (2000). Nouns before verbs in comprehension vs. production: the view from pragmatics. Child Language, 27, 501-520.

[8] Hohle, B., Weissenborn, J., Keifer, D., Schulz, A., and Schmitz, M. (2004). Functional elements in infants' speech processing: The role of determiners in syntactic categorization of lexical elements. Infancy, 5, 341-353.

[9] Kauschke, C., and Stenneken, P. (2008). Differences in noun and verb processing in lexical decision cannot be attributed to word form and morphological complexity alone. Journal of Psycholinguistic Research, 37, 443-452.

[10] Kroll, J. F., and Erika, S. (1994). Category interference in translation and picture naming: evidence for asymmetric connections between bilingual memory representations. Journal of Memory and Language, 33, 149174.

[11] Maxwell, J. A. (1998). Designing a qualitative study. Handbook of Applied Social Research Methods, 69-100.

[12] McRae, K., and Stephen, B. (1998). Automatic semantic similarity priming. Journal of Experimental Psychology: Learning, Memory, and Cognition, 24, 558-572.

[13] Mintz, T. H. (2003). Frequent frames as a cue for grammatical categories in child directed speech. Cognition, $90,91-117$.

[14] Mintz, T. H., Newport, E. L., and Bever, T. G. (2002). The distributional structure of grammatical categories in speech to young children. Cognitive Science, 26, 393-424.

[15] Monaghan, P., Chater, N., and Christiansen, M. H. (2005). The different role of phonological and distributional categories cues in grammatical categories. Cognition, 96, 143-182.

[16] Pinker, S. (1987). The bootstrapping problem in language acquisition. In MacWhinney, Brian (ed. ), Mechanism of language acquisition. Hillsdale, $\mathrm{NJ}$ : Eribaum.

[17] Redington, M., Chater, N., and Finch, S. (1998). Distributional information: A powerful cue for acquiring syntactic categories. Cognitive Science, 22, 425-469.

[18] Shelton, J. R., and Randi, C. M. (1992). How semantic is automatic semantic priming? Journal of Experimental Psychology: Learning, Memory, and Cognition, 18, 1191-1210.

[19] Vigliocco, G., David, P., Vinson, P. J., Willem, J. M., Levelt and Frauke, H. (2004). The role of grammatical gender and semantics in German word production. Journal of Experimental Psychology: Learning, Memory, and Cognition, 30, 483-497.

[20] Von Humboldt, W. (1999). On language: On the diversity of human language construction and its importance on the mental development of the human species. Cambridge, UK: Cambridge University Press. 